\title{
Perceived Challenges and Strategies towards the Attainments of Sustainable Development Goal Three (SDG 3): Evidence from Irewole and Isokan Local Government Areas of Osun State, Nigeria
}

\author{
Aransi, Waliyi Olayemi \\ Department of Adult Education, Faculty of Education, University of Ibadan, Ibadan, Nigeria.
} Email:omoaransi@yahoo.com Tel:+2347030251269

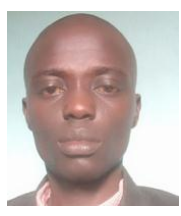

\begin{abstract}
The study examined the perceived challenges and possible strategies towards the attainment of Sustainable Development Goal three (SDG-3), evidenced from Irewole and Isokan Local Government Areas of Osun State, Nigeria. An exploratory research design was adopted for the study. Both qualitative and quantitative instruments were used. However, two-hundred and seventy (270) participants were sampled. Descriptive statistics and thematic analysis were used to analyze quantitative and qualitative data respectively. The empirical outcomes indicated that the perceived challenges towards effective implementations and utilizations of core health and healthrelated projects include; inadequate provision of financial resources; weak personnel management capacity; inadequate involvement of members of the community during the planning stage of the projects; political instability; abandonment of the project; and inadequate utilization of modern technologies for effective management of the projects. In terms of possible strategies, the empirical outcomes revealed the need for bottom-up approach to developmental projects, regular training programs for community members, adequate monitoring and supervision of the projects during implementation, mobilization of financial resources, public campaigns and awareness, effective program evaluation, provision of modern technological equipment and mobilization of human resources by the host community. Recommendation comprised reactivation of abandoned projects, mobilization of physical and financial resources and regular public enlightenment campaigns program to mention a few were suggested.
\end{abstract}

Keywords: Challenges, Strategies, Health, Sustainable development goal, Government policy, Implementation, Attainments JEL Classification: D62, D60, H4, Io0, I18.

Citation | Aransi, Waliyi Olayemi (2020). Perceived Challenges and Strategies towards the Attainments of Sustainable Development Goal Three (SDG 3): Evidence from Irewole and Isokan Local Government Areas of Osun State, Nigeria. Economy, 7(1): 42-51. History:

Received: 17 February 2020

Revised: 19 March 2020

Accepted: 23 April 2020

Published: 7 May 9020

Licensed: This work is licensed under a Creative Commons

Attribution 3.0 License (c)

Publisher: Asian Online Journal Publishing Group
Funding: This study received no specific financial support.

Competing Interests: The author declares that there are no conflicts of interests regarding the publication of this paper.

Transparency: The author confirms that the manuscript is an honest, accurate, and transparent account of the study was reported; that no vital features of the study have been omitted; and that any discrepancies from the study as planned have been explained.

Ethical: This study follows all ethical practices during writing.

\section{Contents}

1. Introduction

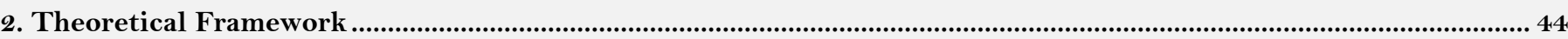

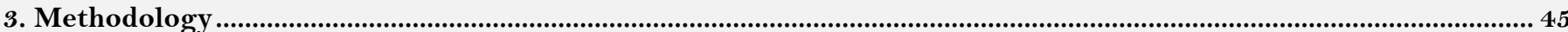

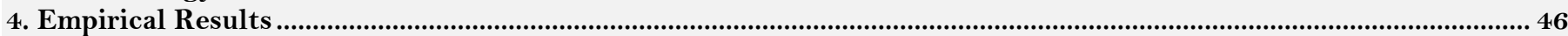

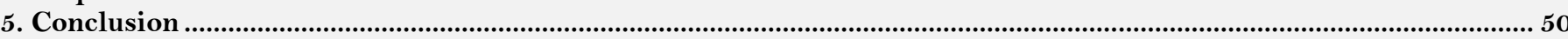

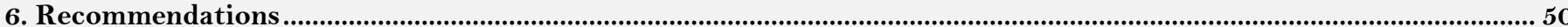

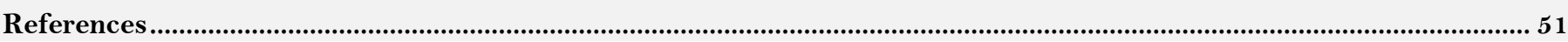




\section{Contribution of this paper to the literature}

This study contributes to the existing literature by identifying some of the perceived challenges militating against effective implementation and utilization of health and health-related developmental programs as well as suggesting workable strategies to be embraced by the concerned community stakeholders.

\section{Introduction}

\subsection{Background to the Study}

Nigeria was among the one-hundred and eighty nine (189) countries from across the globe that endorsed and embraced the United Nations Millennium Declaration in New York in September 2000, which consisted of eight (8) goals, eighteen (18) targets and forty-eight (48) indicators (United Nations, 2003). These goals were enumerated and conceptualized in sequential order of eradicating extreme poverty and hunger; achieving universal primary education; promoting gender equality and empowering women; reducing child mortality rates; improving maternal health; combating HIV/AIDS, malaria, and other diseases; ensuring environmental sustainability and lastly developing a global partnership for development.

However, it is clear to deduce that eradication of poverty and hunger as reiterated in goal one among citizenry could not be attained in isolation, this is due to the fact that three out of these goals were basically on health (Goals four, five and six), while two out of the remaining ones embedded health components (Goals one and seven) such as required volume of protein and vitamin, safe drinking water and sanitation exercise. This may be attributed to the vital role being played by health sector towards the attainment and sustenance of poverty eradication projects as contained in the peoples' notion that 'a healthy individual is a wealthy individual'. In the light of this, it was acknowledged that within the Nigeria context neither extreme poverty and hunger eradication nor core health and health related goals were achieved as at the expiration period of the set goals in 2015 (MGDs, 2015).

Following the expiration of the implementation timeline slated for Millennium Development Goals (MDGs), the international community through the United Nations in collaboration with the Heads of States and Governments of the one-hundred and ninety three (193) member nations, launched the Sustainable Development Goals (SDGs) as a new development agenda. This agenda, also known as Agenda 2030, was framed into seventeen (17) goals, one-hundred and sixty nine (169) targets and two-hundred and thirty (230) indicators (UN, 2017).

These goals are conceptualized and prioritized in the development agenda in hierarchical order of ending poverty; eradicating hunger; ensuring good health and well-being of the people; ensuring quality education for all; achieving gender equality; ensuring provision of clear water and sanitation; ensuring affordable modern energy for all; promoting decent work and economic growth; creating industry innovation and infrastructure; reducing inequalities both within and among countries; achieving sustainable cities and communities; ensuring sustainable consumption and production pattern; controlling adverse climate action; sustaining life below water; protecting life on land, promoting peace, justice and strong institutions and lastly strengthening global partnership (UN, 2017). It is inferred from the document that only goal three of the Agenda 2030 focused on health of the people as contrary to MDG in which goals four, five and six were basically on health while goals one and seven had health components.

The goal three of the development agenda is aimed at ensuring healthy lives and promote well-being for all at all ages. This goal according to the Business Reporting on the SDGs (2016) was predicated on nine main targets. First, reduce the global maternal mortality ratio to less than 70 per 100,000 live births. Second, end preventable deaths of new-born and children under 5 years of age, with all countries aiming to reduce neonatal mortality to at least as low as 12 per 1,000 live births and under-five mortality to at least as low as 25 per 1,000 live births. Third, end the epidemics of AIDS, tuberculosis, malaria and neglected tropical diseases and combat hepatitis, water-borne diseases and other communicable diseases. Fourth, reduce by one third premature mortality from noncommunicable diseases through prevention and treatment and promote mental health and well-being. Fifth, strengthen the prevention and treatment of substance abuse, including narcotic drug abuse and harmful use of alcohol. Sixth, by 2020, halve the number of global deaths and injuries from road traffic accidents. Seventh, ensure universal access to sexual and reproductive health-care services, including for family planning, information and education, and the integration of reproductive health into national strategies and programs. Eighth, achieve universal health coverage, including financial risk protection, access to quality essential health-care services and access to safe, effective, quality and affordable essential medicines and vaccines for all and lastly to substantially reduce the number of deaths and illnesses from hazardous chemicals and air, water and soil pollution and contamination. This buttressed the notion that good health is not only a predictor of growth but also a prominent component of the general well-being of the country's population. This had made people to see health as a merit good universally, such that, a minimum of which should be entitled to by each and every individual regardless of the ability to pay. For instance, in health care markets, the equity issue has been manifested by widespread public subsidization or direct provision of health care to the general public irrespective of socio-economic status of the majority, as an individual needs some minimum amount of health human capital to survive. However, it was indicated that good health is an asset to the nation as it has both economic and non-economic values. Mwabu (2007) acknowledged that there are large returns to health improvements in developing countries. This is because, consumption of health care, particularly preventive care, is often associated with positive externalities. For example, treatment of a patient with an infectious illness does not only benefit the person treated, but also other persons because they are protected from exposure to infection. Similarly, immunization of an individual against a communicable disease protects other people from the disease. Moreover, health improvements in developing nations like Nigeria can be achieved through implementation of simple interventions such as dietary supplements, control of parasitic and droplet diseases like Corona Virus also known as COVID 19, and pro-poor social expenditures among others.

However, evidence from Levels and Trends in Child Mortality Report (2015) revealed that 5.9 million children under 5 years died in 2015, with a global under-five mortality rate of 42.5 per 1000 live births. This was reported to be highest in Sub-Saharan Africa including Nigeria, in which 1 child in 12 dies before their fifth birthday, 
followed by South-East Asia where 1 in 19 dies before reaching 5 years. It was acknowledged that most of these deaths were from preventable diseases. Also, the period between 2000 and 2015 witnessed a 46 per cent reduction in HIV incidence; a 17 per cent decline in the incidence of tuberculosis; a 41 per cent decrease in the incidence of malaria; and a 21 per cent drop in people requiring mass or individual treatment and care for neglected tropical diseases. The risk of dying between the ages of 30 and 70 from one of four main non-communicable diseases (NCDs)-cardiovascular disease, cancer, diabetes or chronic respiratory disease-fell from 23 per cent to 19 per during that period. This was not rapid enough to meet the 2030 target. And that nearly 800,000 suicides occurred worldwide in 2015, with men about twice as likely to die by suicide as women. In 2013, around 1.25 million people died from road traffic injuries, an increase of 13 per cent since 2000. In 2012, household air pollution from cooking with unclean fuels and inefficient technologies led to an estimated 4.3 million deaths; another 3 million deaths were attributed to ambient air pollution from traffic, industrial sources, waste burning and residential fuel combustion.

Furthermore, the risk of acquiring infectious diseases varies greatly depending on socioeconomic status of the households in terms of poverty level, housing conditions and gender attributes-for example, in the case of HIV infection in women, and tuberculosis in men as well as environmental conditions. Mortality could be caused by exposure to unsafe water, sanitation and hygiene. For instance, in 2012, 871000 deaths (mostly from infectious diseases) were caused by the contamination of drinking water, bodies of water (such as rivers and reservoirs) and practices resulting from inadequate or inappropriate services. Almost half (45\%) of these deaths occurred in the African countries where 13\% of the global population lived (WHO, 2015 and 2016). In 2014, there were 9.6 million new tuberculosis cases (133 per 100 OOO population) and 1.5 million tuberculosis deaths, including 0.4 million deaths among HIV-positive people. Therefore, the largest number of new tuberculosis cases occurred in the SouthEast Asia region and Western Pacific region, estimated at 58\% of new cases globally. Africa carried the most severe burden, with 281 cases per 100 o00 population (Global Tuberculosis Report, 2015). In addition, in 2015, the malaria incidence rate was 91 per 1000 persons at risk, with an estimated 214 million cases and 438 o00 deaths (more than two thirds of which occurred in children under 5 years of age). Sub-Saharan Africa has the highest burden, with an incidence rate of 246 per 1000 persons at risk, accounting for roughly $90 \%$ of all cases and deaths globally (World Malaria Report, 2015). Globally, an estimated figure of 422 million adults were living with diabetes in 2014, which was higher than 108 million in 1980. The global prevalence of diabetes has nearly doubled since 1980 , rising from $4.7 \%$ to $8.5 \%$ in the adult population. This reflected an increase in associated risk factors such as being overweight or obese. Over the past decade, diabetes prevalence has risen faster in low- and middleincome countries than in high-income countries. Diabetes caused 1.5 million deaths in 2012. Higher-than-optimal blood glucose caused an additional 2.2 million deaths, by increasing the risks of cardiovascular and other diseases. Forty-three percent of these 3.7 million deaths occur before the age of 70 years. The percentage of deaths attributable to high blood glucose or diabetes that occurs prior to age 70 is higher in low- and middle-income countries than in high-income countries (International Diabetes Federation, 2017).

However, different factors have been identified for being responsible for the failure of previous developmental programs including MDGs in the attainment of the enumerated goals within the time frame. Some according to Ajiye (2014) included insufficient human capacity needed for both formulation and implementation of the development programs, inadequate and unreliable data system, financial challenge and indiscipline and endemic corruption. Akpama, Bessong, and Bessong (2017) averred that this would be partially hinged on the ineffective participation of adults during both formulation and implementation phases of the program. This is premised on the belief that adults who are well equipped with requisite basic knowledge, experiences and skills are expected to constitute the fulcrum around which the successful implementation of the developmental program depend. Besides, prevalent of wide gap between the rich and the poor individuals (Anigbogu \& Ndubuisi-Okolo, 2019) high level of insecurity toward lives and developmental projects (Ndubuisi-Okolo \& Anigbuogu, 2019) poor governance and lack of political will (Adekola, Allen, Adeloye, Olawole-Isaac, \& Adediran, 2017) gap in knowledge and awareness between people in rural and urban centers (Ogbodo \& Okoro, 2015) and lack of reliable data, weak human capacity resources, high level of corruption and cultural diversity, lack of local participation and empowerment, and loss of focus on sustainability (Ajiye, 2014). It is against this background that the study was designed to examine the perceived challenges and possible strategies towards the attainment of SDG 3 (health) programs, evidence from Irewole and Isokan Local Government Areas of Osun State, Nigeria.

\subsection{Objective of the Study}

The main objective of this study was to examine the perceived challenges and possible strategies towards the attainments of Sustainable Development Goal 3 in Osun State, Nigeria. While, specific objectives are to;

i. Find out the challenges towards effective implementations of SDG 3 (good health) programs within the studied area.

ii. Suggest the possible strategies for effective implementation and utilization of SDG 3 (good health) programs in Osun State.

\subsection{Research Questions}

The following research questions guided the study.

i. What are the perceived challenges towards effective implementations of SDG 3 (good health) programs within the studied area?

ii. What are the possible strategies towards effective implementation and utilization of SDG 3 (good health) programs in Osun State, Nigeria?

\section{Theoretical Framework}

\subsection{Community-Driven Development Theory}

The theory as a part of the World Bank initiative, was postulated by International Development Association (IDA). This initiative was to help the world's poorest countries in reducing poverty by boosting economic growth, reducing inequalities, and improving people's living conditions. IDA's work covers primary education, basic health 
services, clean water and sanitation, agriculture, business climate improvements, infrastructure, and institutional reforms. The Community Driven Development (CDD) theory is an approach that gives control of the development decisions and resources to community groups and stakeholders of the community. Under this theory, poor communities are expected to receive funds from the concern bodies where in this case can be either government or non-governmental organizations, decide on their use, plan and execute the chosen local projects, and monitor the provision of services that result (International Development Association (IDA), 2009). This indicated that poor people are often viewed as the target of poverty reduction efforts as put forward by this theory. Community Driven Development (CDD) treats poor people and their institutions as assets and partners in development process. CDD holds the view that given clear rules of the game, in terms of access to appropriate support, poor men and women can effectively organize to provide goods and services that meet their priorities (Alkire, 2001). In spite of this, the theory fails to take into cognizance some situational imposed constraints that could facilitate members of the community or society inability to access sound health care facilities when the need arise and thereby remain in poverty.

\subsection{Situational Theory of Poverty}

This was propounded by Rodman (1963). This theory was a response to the culture of poverty theory. It views poverty as a reaction to situational constraints and not as an issue of culture. This is because, poverty results from imposed constraints like low income, lack of awareness, lack of empowerment, unemployment and illness. The theory holds that people are poor due to the fact that they find themselves in a situation of no resource and opportunities for them to advance their welfare. It lays emphasis on the structural conditions that lead to poverty. Situational poverty differs from the culture of poverty theory because it does not assume the pre-existence of a subculture that makes the behavior of the poor to become coherent and solid. It implies that in the absence of this sub-culture, the poor can easily get out of poverty if imposed constraints are tackled and address by the concerned individuals in the helms of community's' affairs.

\section{Methodology \\ 3.1. Research Design}

An exploratory research design was employed. This encouraged combination of qualitative and quantitative approaches to research instruments (Creswell, 2014; McMillan \& Schumacher, 2010; Sogunro, 2015). The beauty of this design was that the strengths of one form of data collection would offset the weaknesses of the other form. Hence, it provides ease triangulation of data sources, and consequently enhances the credibility of the findings (Creswell. \& Plano, 2011). As a result, qualitative approach most especially Key Informant Interview (KII) and participant's observation technique were employed to solicit information on the perceived challenges and strategies towards Sustainable Development Goal three attainment. Quantitative segment comprised different items on the subject matter. All participants in the qualitative segment of the design were not involved in the quantitative component so as to avoid duplication of ideas.

\subsection{Population of the Study}

The population of the study comprised all youths participating in different kind of empowerment programs spearheaded by the state government tagged 'Youth Empowerments Scheme (OYES)'. Community stakeholders like high chiefs in palace, water corporation staff and health personnel who are in charge of providing or implementing programs or projects design to raise people's living standard within the community such as bore hole, health care center, tap water and channeling of erosion to mention a few. This is because, all these aforementioned programs were expected to be initiated with the good intension of achieving sound health among citizenry which was in tandem with SDG 3 if achieved.

\subsection{Sample Size and Sampling Technique}

Two local governments were purposively sampled for the study. They are Irewole and Isokan Local Government Areas of Osun State. This was due to the fact that the sampled communities formed the backbone for assessing effectiveness of development programs put in place by the government across the state since inception of OYES in 17th December, 2010. They had sample frame of four-hundred and nineteen (419) and three-hundred and ninety four (394) respectively totaling eight-hundred and thirteen (813) participants in the said empowerment program-Osun Youths Empowerment Scheme (OYES). Two-hundred and seventy (270) sample were selected with the aid of simple random and purposive sampling techniques. However, one-hundred and fifty (150) and onehundred and twenty (120) were sampled from Irewole and Isokan Local Government Area of Osun State respectively. Simple random sampling technique was employed as a result of the fact that each element in the sample frame would have equal chance of being involved in the study. For purposive sampling technique, this allows the researcher to carefully and consciously chooses the subjects to be included in the sample so that the sample can be developed for his needs. In the light of this, only those who had minimum of Nigeria Certificate in Education or Ordinary National Diploma certificate or its equivalent were sampled and used in the research. This is to ensure efficient and effectiveness administration of the instrument on the respondents, due to their ability to read and understand each of the items enumerated in the instrument.

Furthermore, Yaro Yamane Technique was used to determine the sample size taken from the sample frame. This technique was useful and relevant to determine sample size through statistical computation where the finite population is known to be eight-hundred and thirteen (813). This is to reduce error and to ensure that the study is not porous, than determining the size by mere approximation percentage that is not statistically backed up. This is consequent upon the fact that sample size is expected and better determined statistically in order to ensure appropriateness of the procedure (Uzoagulu, 2011). 


\subsection{Instrumentation}

Structured questionnaire which was planned on various rating scales, key informant interview and participant observation were used for gathering relevant data for the study. The questionnaire was developed by the researcher which titled "Perceived Challenges and Strategies towards Sustainable Development Goal 3 Attainment Questionnaire (PCS-SDG3 AQ)". The questionnaire had three sections, section A dealt with demographic information of the respondents, while remaining sections were basically designed in structure form to cater for the research questions and objectives. The responses were planned on four points Likert-scale rating which ranged from Strongly Agree, $(\mathrm{SA})=4$, Agree $(\mathrm{A})=3$, Disagree $(\mathrm{D})=2$ to strongly disagree $(\mathrm{SD})=1$.

\subsection{Validity of the Instrument}

In order to effectively ensure the validity of the instruments used for this study, the instruments were subjected to content validity measurement which involves face validity and predictive validity. On face and content validity, the items are presented in simple language for easy understanding by the respondents and are also logically and systematically arranged in line with the research questions and objectives. The researcher ensured the validity of the instruments by making sure that the contents of the instruments are consistent with both the objectives and research questions of the study.

\subsection{Reliability of the Instrument}

The instrument was trial-tested among forty (40) N-power participants serving in various public schools in Irewole and Isokan Local Government Areas of Osun State which are not part of the respondents slated for the study. The internal consistency reliability coefficient was obtained with the aid of Cronbach Alpha reliability technique. The justification for using Cronbach Alpha reliability technique was based on the fact that the items on research instrument, that is questionnaire have no right or wrong answer and it allowed respondents to rate the degree or extent to which they agree or disagree with a statement on a particular scale. However, the Cronbach Alpha reliability test revealed 0.69 and 0.80 for perceived challenges and possible strategies respectively. The outcomes posited that the instrument was suitable, appropriate, adequate and reliable for the research work.

\subsection{Method of Data Administration}

The data were collected through questionnaire, personal interview and participant's observation. The questionnaire was administered to the respondents by the researcher alongside with a trained research assistant. The research assistant was briefed on the objectives, guidance, approach, and explanations to the respondents on how to complete the questionnaire. In addition, the researcher directly engaged in personal interview and participant observation so as to obtain information as well as to have in-depth knowledge of the research topic through face to face interaction. This instrument was used because it gives opportunity for deeper probing into issues under investigation.

The administration of the instrument took place on two Wednesdays (that is 12th and 19th June, 2019) at Irewole Local Government secretariat, Ikire and African Church Middle School Apomu in Isokan Local Government Area of Osun State respectively. This was because, the target population usually converged on every Wednesdays at the aforementioned venues or some other places for physical exercises and dissemination of vital information across by their respective leaders. The researcher and his assistants collected the instrument immediately after filling and by this two-hundred and seventy (270) respondents submitted which accounted for one-hundred per cent $(100 \%)$ return rate.

\subsection{Method of Data Analysis}

The quantitative data collected were analyzed using descriptive statistics. This comprised mean and standard deviation. In addition, thematic analysis was used for the qualitative component of the generated data, that is, for outcomes from Key Informant Interview and participant's observation.

\section{Empirical Results}

4.1. Analysis Based on Demographic Characteristics of the Participants

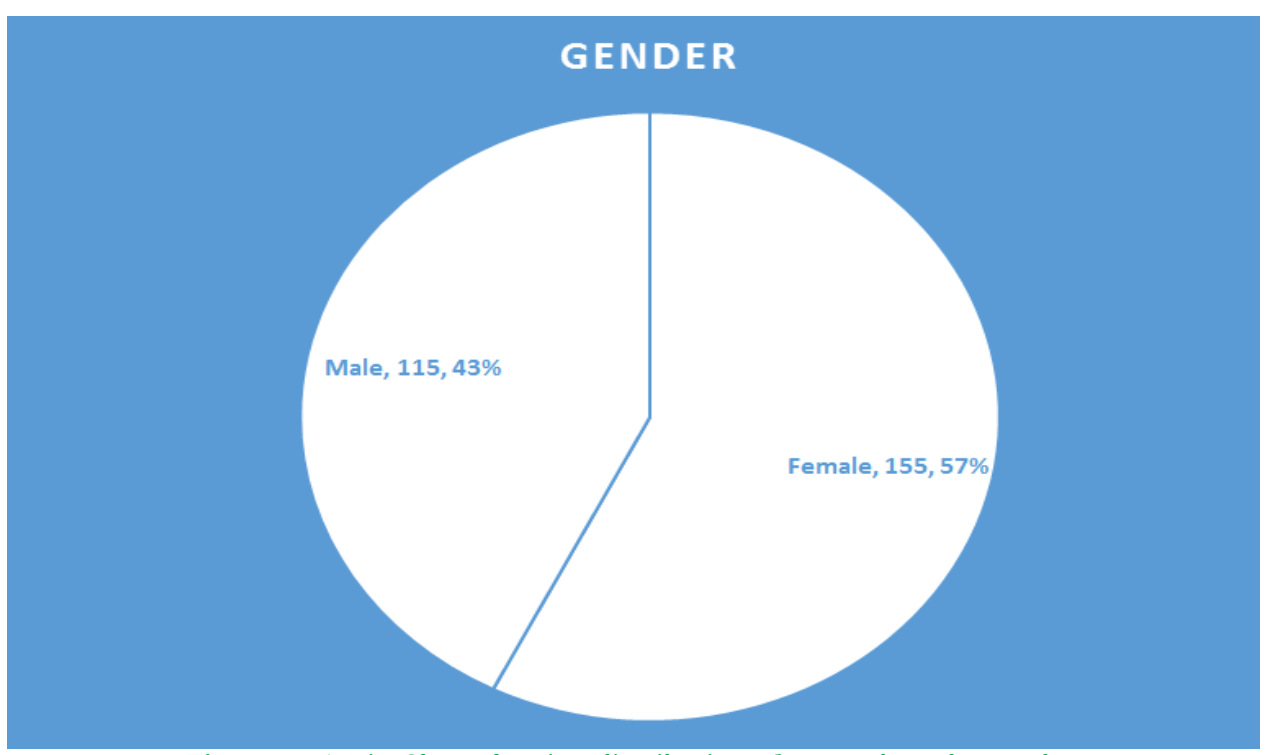

Figure-1. A Pie-Chart showing distribution of respondents by gender. 
Figure 1 is expressed in percentage form. It revealed that one-hundred and fifty five (155) of the respondents which represented $57 \%$ of the total participants are female going by their gender, while the remaining one-hundred and fifteen (115) which accounted for $43 \%$, were male. It can be deduced that majority of the participants involved in the aforementioned empowerment programs were female as having $57 \%$. This is to say that the empowerment program was gender sensitive at both formulation and implementation phases. As it was packaged towards the attainment of gender equality and women empowerment targets of the developmental agenda. The implication of this distribution is that it conforms to the legal frameworks of promoting, enforcing and monitoring equality and non-discrimination on the basis of sex.

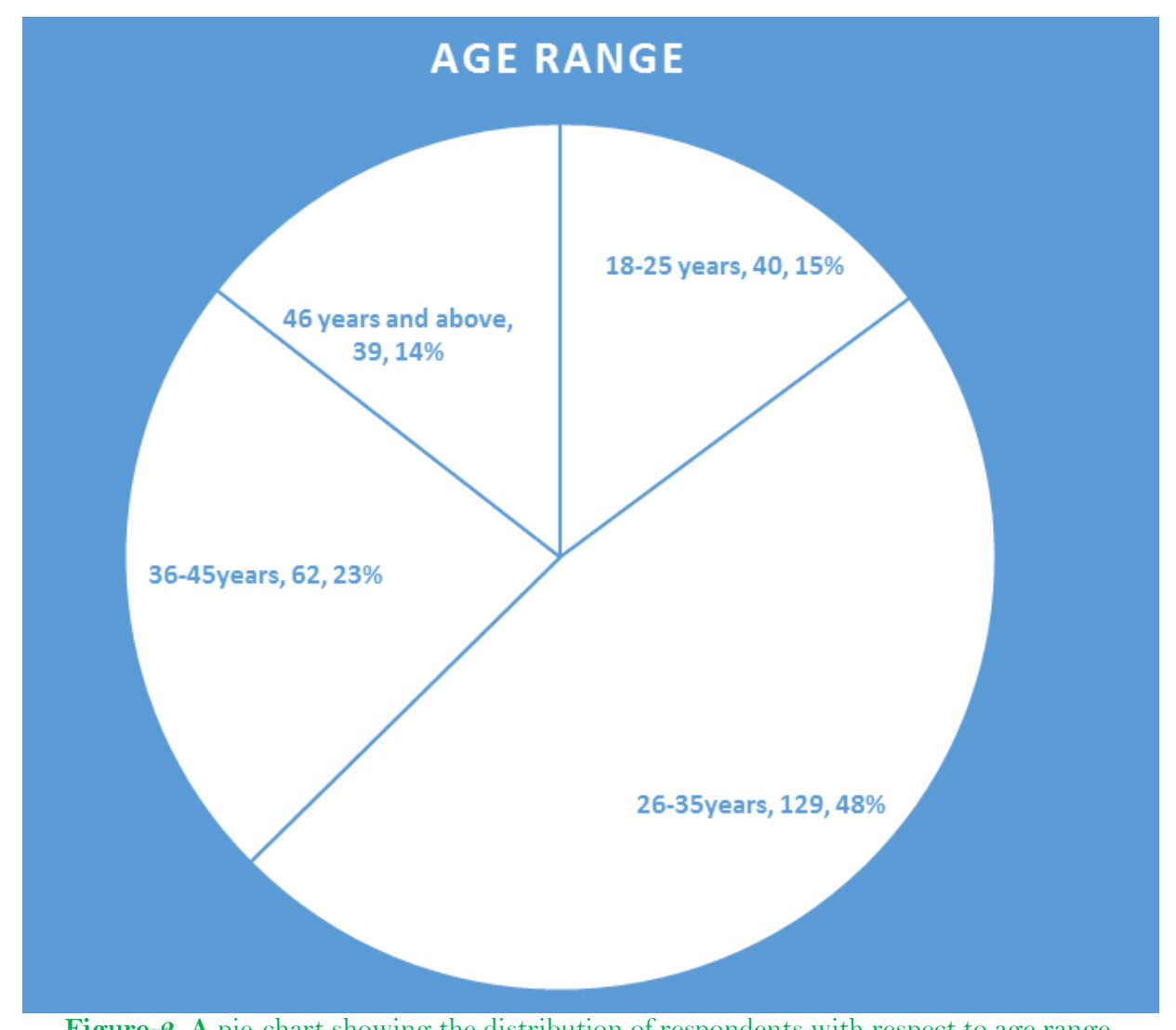

Figure-2. A pie-chart showing the distribution of respondents with respect to age range.

Figure 2 that is pie-chart is expressed in percentage, it indicated that $15 \%$ of the respondents are between 18 25 years of age, $48 \%$ of them are between $26-35$ years of age, $23 \%$ and $14 \%$ of the participants are between $36-45$ years and 46 years and above respectively. It is revealed that majority of the respondents were within their youthful age of 26-35 years of age range as having $48 \%$ of the total respondents. It is inferred that the rationale for engaging majority of youths in the empowerment may in part be attributed to presence of physical, cognitive, social, and emotional characteristics needed for the task under consideration. The program was dominated by adults with the notion that they would serve as conveyor belts to fast track the actualization of the development programs situated within the community.

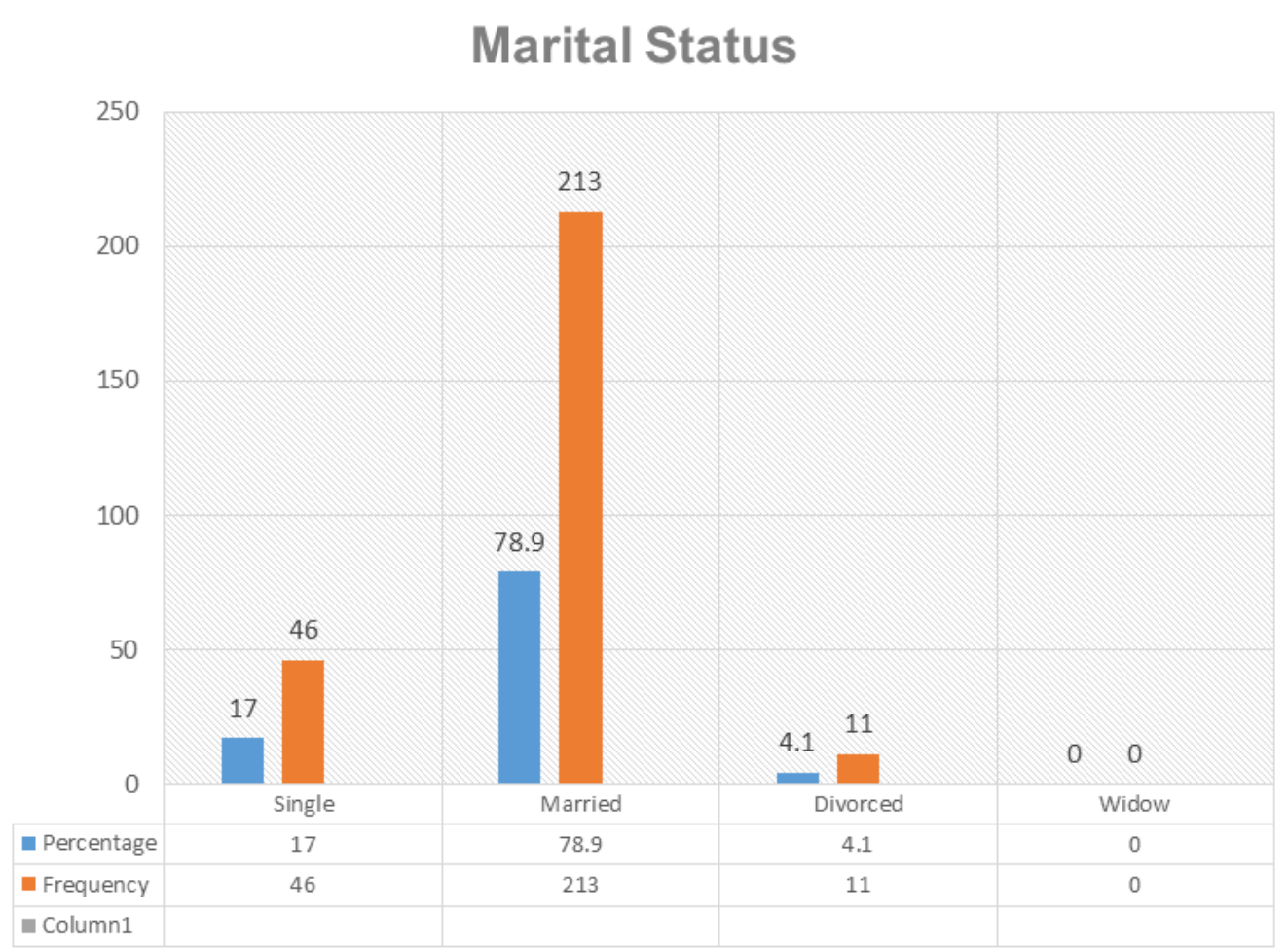

Figure-3. Bar-chart showing the distribution of respondents by marital status.

Figure 3 that is bar-chart is expressed in both percentage and frequency of the participants. The results indicated that forty-six (46) of the respondents which represented $17.0 \%$ of the total participants are single going 
by their marital status, two-hundred and thirteen (213) and eleven (11) of them which represented $78.9 \%$ and $4.1 \%$ were married and divorced respectively. While, none of them were widow. It can be deduced that majority of the participants involved in the study were married as having $78.9 \%$ of the entire respondents used in the research. It is inferred that majority of the participants own their immediate family as having two-hundred and thirteen out of two-hundred and seventy respondents. This depicted that one of the rationale for introducing and initiating empowerment exercise would be for the beneficiaries to meet their respective basic needs.

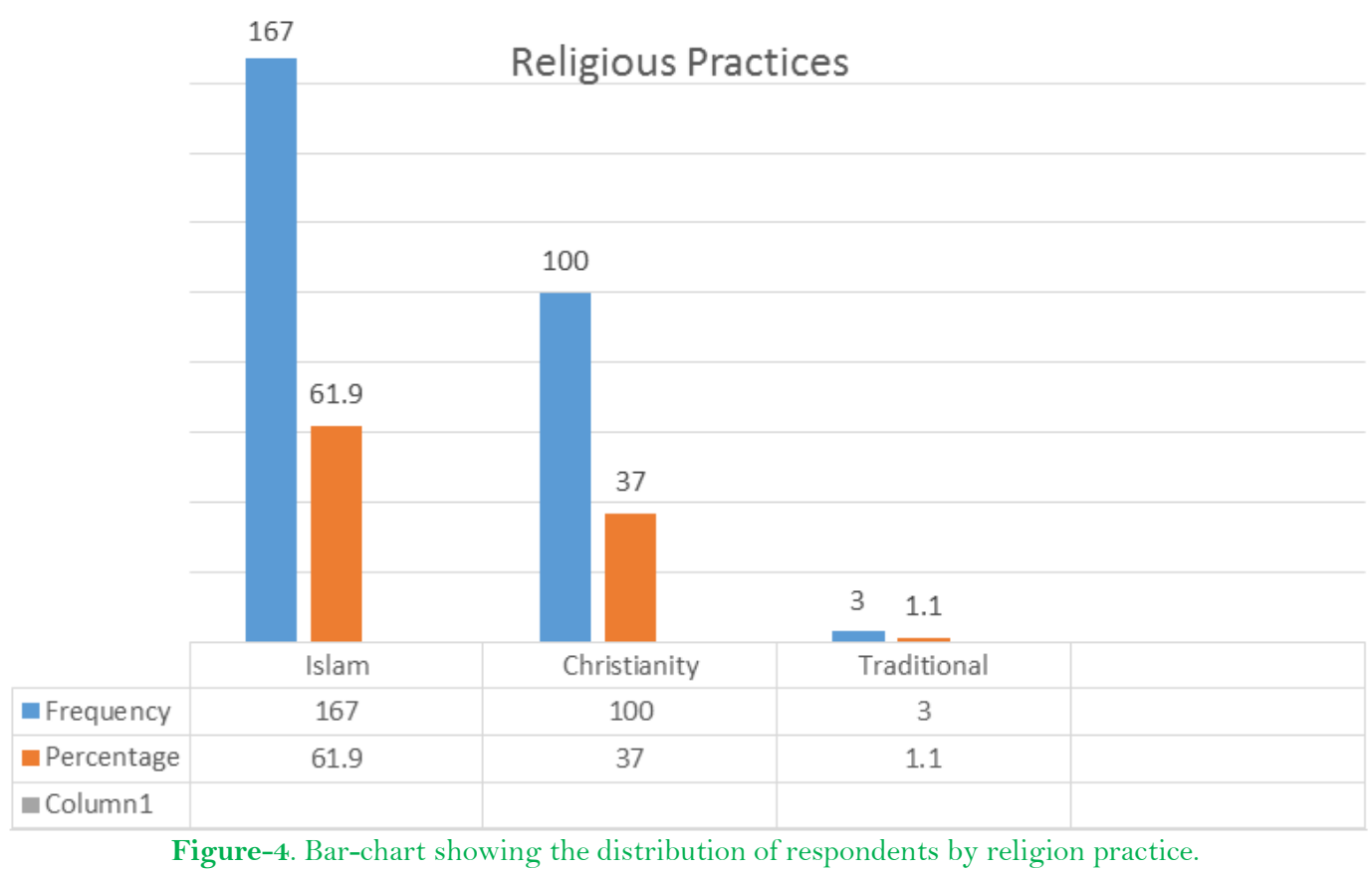

Figure 4, that is bar charts showed the distribution of respondents on the basis of their religious practice. It displayed that one-hundred and sixty seven (167) of the participants which represented $61.9 \%$ claimed to be Muslim. One-hundred (100) which amounted to $37 \%$ of them are Christianity by their claim, while three (03) which accounted for $1.1 \%$ of the total participants are Traditional worshipers. Hence, majority of the participants involved in the research are Muslim as having $61.9 \%$ of the overall respondents, followed by Christian while the least participants are Traditional worshippers.

\section{PARTICIPANTS}

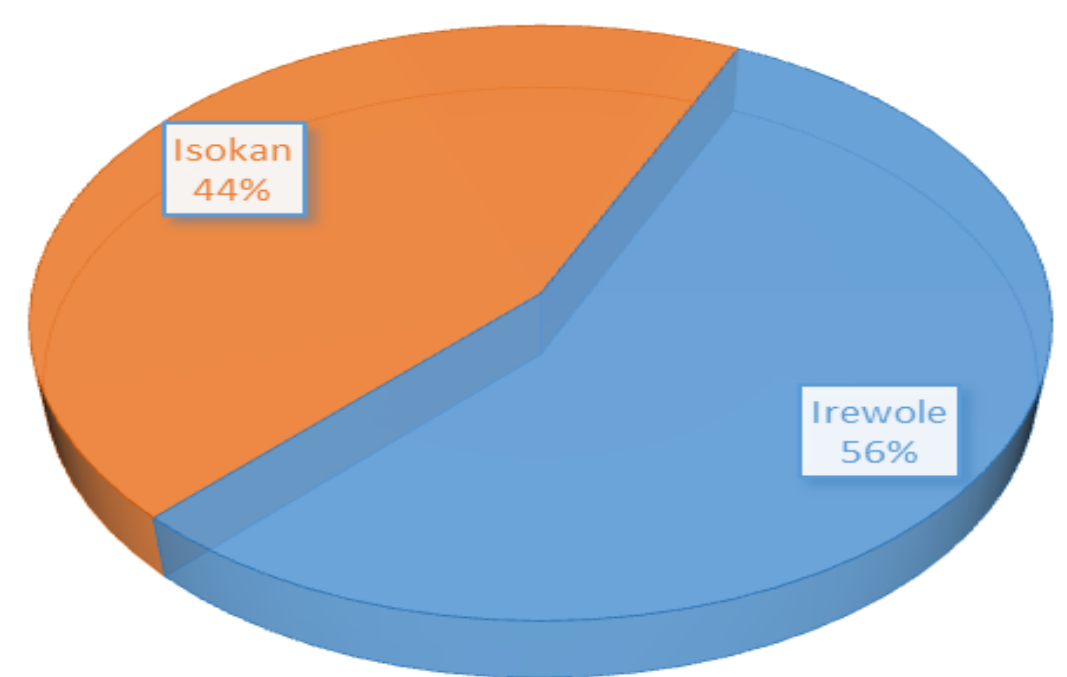

Figure-5. Pie-chart showing the distribution of respondents by local government.

Figure 5 that is pie-chart is expressed in percentage. The chart exhibited that one-hundred and fifty (150) participants which amounted to $56 \%$ were selected in Irewole Local Government Area of Osun State, while onehundred and twenty (120) which accounted for 44\% were chosen from Isokan Local Government Area. This reflected that number of sample taken from Irewole Local Government was slightly higher than the one selected from Isokan Local Government Area. This is due to the fact that the number of beneficiaries engaged in Irewole was greater than those involved in Isokan for the same exercise. 


\section{Qualifications}

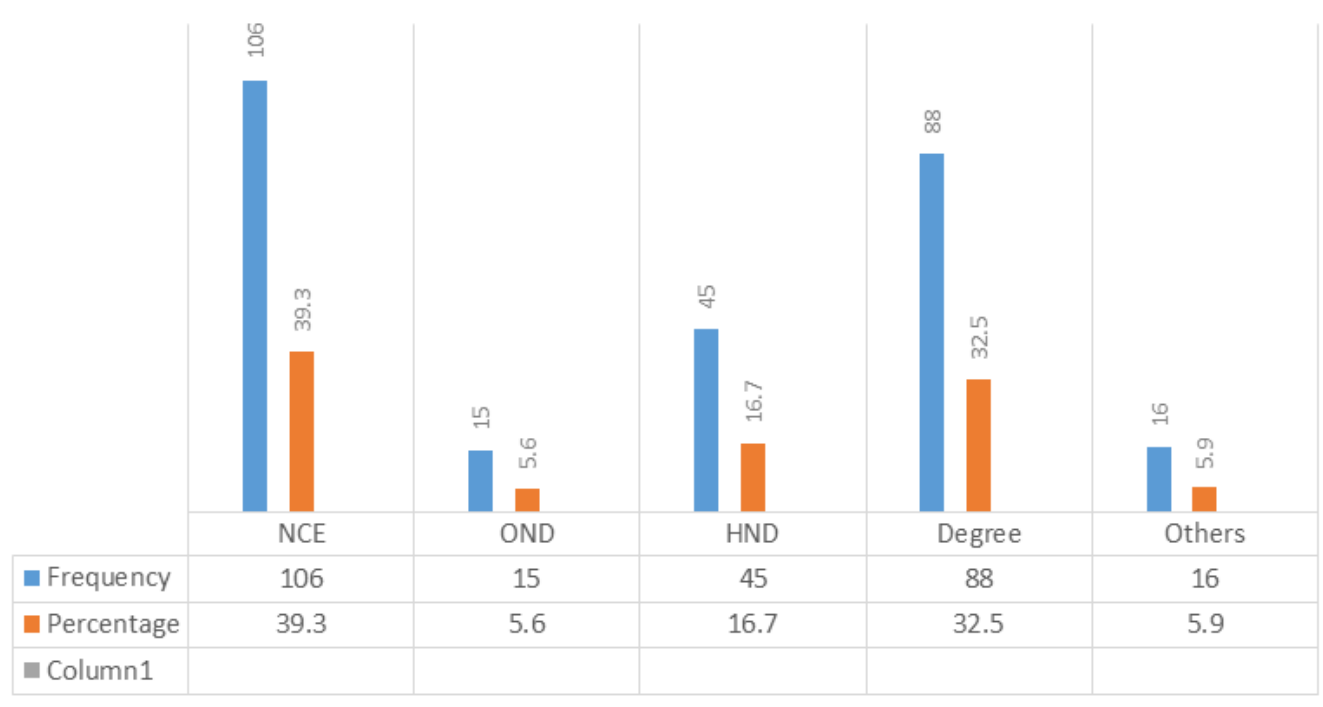

Figure-6. Bar-chart showing the distribution of respondents by educational qualifications.

Figure 6 that is bar chart showed distribution of respondents with respect to their educational qualifications. The chart indicated that one-hundred and six (106) respondents had Nigeria Certificate in Education (NCE) which represented $39.3 \%$, fifteen (15) of them which accounted for $5.6 \%$ had Ordinary National Diploma certificate, fortyfive (45) and eight-eight (88) of the respondents which amounted to $16.7 \%$ and $32.5 \%$ had Higher National Diploma and First Degree certificates respectively, while, sixteen (16) of them had other certificates which may include Postgraduate in Education and second degree certificates among others. Therefore, majority of the participants had Nigeria Certificate in Education (NCE). The implication is that they can be used to augment teaching staff at both secondary and primary schools where sufficient teaching personnel is lacking.

\subsection{Analysis Based on Research Questions and Discussion of Findings}

Research Question 1: What are the perceived challenges militating against effective implementations and utilizations of SDG 3 (good health) programs within the studied area?

Table-1. Descriptive statistics showing the respondents view towards the perceived challenges militating against effective implementations and utilizations of SDG 3 (good health) programs within the studied area.

\begin{tabular}{|c|c|c|}
\hline Items & Mean & S.D \\
\hline Inadequate financial resources towards health care services & 3.25 & 0.72 \\
\hline Weak personnel management capacity which usually leads to brain drain among health workers & 2.89 & 0.67 \\
\hline Inadequate supervision and evaluation of the health programs or projects & 1.50 & 0.19 \\
\hline $\begin{array}{l}\text { Inadequate involvement of members of the community in the planning process and mobilization of the } \\
\text { people towards health projects }\end{array}$ & 3.76 & 0.88 \\
\hline Lack of adequate land space for building capital projects for health care delivery. & 0.12 & 0.01 \\
\hline Political instability due to change in government & 3.33 & 0.74 \\
\hline Abandonment of the health care project. & 3.00 & 0.69 \\
\hline $\begin{array}{l}\text { Inadequate utilization of modern technologies for effective management of the health projects and } \\
\text { programs. }\end{array}$ & 3.05 & 0.69 \\
\hline Grand weighted Average & \multicolumn{2}{|c|}{2.61} \\
\hline
\end{tabular}

Note: N= 270 SA: Strongly Agree = 4, A: Agree = 3, D: Disagree = 2 and SD: Strongly Disagree = 1. Decision Value: Negative $=0.00-2.00 \quad$ Positive $=2.01-$
4.00.

Table 1 exhibited the participants' perspective towards the perceived challenges militating against effective implementation and utilization of SDG 3 (good health) programs within the studied area. The empirical findings showed that the perceived challenges towards effective implementation and utilizations of developmental projectshealth and health related programs comprised inadequate provision of financial resources, weak expert or personnel management capacity, inadequate involvement of members of the community during the planning stage of the projects, political instability in terms of change in government, abandonment of the project before the completion phase, and inadequate utilization of modern technologies for effective management of the projects. This is because, the mean values of 3.25, 2.89, 3.76, 3.33, 3.00, and 3.05 respectively which were within the positive region of decision criterion. On the other hand, it was revealed that inadequate supervision and evaluation as well as provision of needed land space for building capital projects (that is hospitals, health centers) were not the main factors that affected effective implementations and utilizations of the developmental programs. This is buttressed with the mean values of 1.50 and 0.12 which were less than the grand weighted average.

Ajiye (2014) corroborated this by identifying factors like insufficient supply of human resources, inadequate and unreliable data system as well as financial challenges as some of the obstacle guiding against effective implementation of developmental projects. Similarly, Benyin and Ugochukwu (2015) were of the view that challenges to proper implementation of developmental projects range from the non-involvement of citizens in the formulation of policies, lack of adequate human resources or capital, corruption and lack of credible leadership among others. In his own research, Dike (2010) concurred that the infrastructure facilities and institutional arrangement vis-à-vis weak technological capability as well as bad governance constituted to the hindrances towards effective implementation and utilization of developmental projects in developing countries like Nigeria. Igbokwe-Ibeto (2015) supported this by acknowledging that government incur huge financial losses due to poor project monitoring and evaluation. In addition, this is in consonance with the review analysis conducted by Ayodeji 
et al. (2017) in which late start-up activities, limited funding, lack of constant evaluation, weak coordination and duplication of developmental projects and unhealthy competition among donors of the developmental projects were identified as some of the challenges hindered the effective evaluation of hunger related developmental programs. In the same vein, the participant's observation and Key Informant Interview (KII) conducted on the subject matter at community level on Monday 24th June, 2019 revealed inter alia as thus;

'It was observed by the researcher that in one of the two communities under consideration a very big government hospital (tagged general hospital) had been abandoned for years. Though, an alternative was made available for the people within that community but the physical structure and other sophisticated health equipment available in the abandoned one during operation could not be compared with what is obtainable in the existing one. It was also noticed that stakeholders of the two communities were ready to release land for capital projects whenever the need arises but not all developmental projects like borehole water facilities and public toilet installed were effectively functioning as at time of investigation. Besides, it was acknowledged through key informant interview that majority of the developmental projects are usually decided upon by people in the helms of affairs which indirectly hinder the input of members of the community at the policy formulation and implementation stage of the project. Finally, it was acknowledged that political instability through change in government could sometimes be beneficial if and only if people in the community have viable representative in the existing cabinet but detrimental if otherwise and even when there is high level of opposition to the ruling party in the community.'

Research Question 2: What are the possible strategies towards effective implementation and utilization of SDG 3 (good health) programs in Osun State, Nigeria?

Table-2. Descriptive statistics showing the respondents towards the possible strategies for effective implementation and utilization of SDG 3 (good health) programs in Osun State.

\begin{tabular}{|c|c|c|}
\hline Items & Mean & S.D \\
\hline $\begin{array}{l}\text { Community members should be involved during formulation and implementation phases of the } \\
\text { health and health related programs. }\end{array}$ & 3.05 & 0.69 \\
\hline $\begin{array}{l}\text { Government and good spirited individuals should on regularly basis organize training programs for } \\
\text { health personnel to enable them effective handle modern technologies. }\end{array}$ & 3.27 & 0.76 \\
\hline Provision of adequate land space for health projects. & 0.15 & 0.03 \\
\hline Adequate monitoring and supervision of the health projects instituted in the community. & 3.35 & 0.79 \\
\hline Proper finance of health projects by stakeholders to enhance the standard of living in the community. & 3.01 & 0.66 \\
\hline Constant and effective evaluation of the health projects by the stakeholders. & 3.20 & 0.75 \\
\hline Provision of modern health equipment. & 3.04 & 0.69 \\
\hline Public campaign on health and health related programs & 3.04 & 0.69 \\
\hline Mobilization of human resources by the community members & 3.56 & 0.82 \\
\hline Grand weighted Average & \multicolumn{2}{|c|}{2.46} \\
\hline
\end{tabular}
2.01-4.00.

Table 2 contained the participants' perspective towards the strategies for enhancing effective implementation and utilization of SDG 3 (good health) programs in Osun State. The empirical outcomes revealed that participatory approach to developmental projects, organization of constant training programs for community members, adequate monitoring and supervision of the projects, proper finance to enhance the standard of living in the community, public campaign on projects like hospitals, health centers, effective evaluation of the community projects, provision of modern technological equipment and mobilization of human resources by the community were some of the strategies through which effective implementation and utilization of SDG 3 (good health) programs could be achieved as having mean values of 3.05, 3.27, 3.35, 3.01, 3.04, 3.20, 3.04 and 3.56 which were within the positive region of the decision rule. On the other hand, provision of adequate land space for projects like farm settlements, water borehole was not considered as a viable strategies for effective implementation of developmental project as attracted mean value of 0.15 , this could be attributed to the fact that provision of land for developmental project had not been a barrier as the stakeholders of the communities under considerations are always ready to donate land whenever the need arises. This is in tandem with submission made by Igbokwe-Ibeto (2015) in which adherence to due process in all facets of project planning and management, involvement of the people of the grassroots in project initiation, formulation and execution, insistence on continuity on government projects irrespective of change of government or its personnel, availability of visionary and missionary leadership to mention a few were enumerated as way forward.

\section{Conclusion}

The study concluded that bottom-down approach or policy, inadequate mobilization of both human and material resources among others were identified to have contributed to slow rate of implementation and utilization of developmental projects among the people of the communities under investigation. It is also concluded that organization of constant training programs for community members, adequate monitoring and supervision of the projects, proper finance to enhance the standard of living in the community, public campaign on projects like hospitals, health centers and effective evaluation of the community projects were some of the strategies towards attainment of SDG-3.

\section{Recommendations}

Based on the outcomes that originated from this research work, the following recommendations are suggested for stakeholders as thus:

i. Community stakeholders both governmental and non-governmental bodies are advised to monitor and supervise the developmental projects most especially those that are in line towards the attainment of SDG-3 sited within their society and at the same time find a means of reactivating the abandoned projects, as a result of political instability through change in government. 
ii. Government in conjunction with other community stakeholders should make provision for all forms of required physical and financial resources which would stimulate and facilitates effective implementation and utilization of development projects among the people in the community.

iii. Government and Non-Governmental organizations who are in charge of formulating and implementing developmental projects should give room for community members' input during policy formulation. As this would allow the community stakeholders to identify the most pressing needs for the people of the community rather than installing anyone.

iv. Stakeholders are advised to adequately finance all development projects, most especially, those which are in tandem with Sustainable Development Goal three. As this will facilitate the attainment of the targets enumerated under this goal with resultant multiplier effect on others.

v. Mass media agents should on regular interval disseminate prominent basic literacy programs which are embellished with health knowledge and information. As this will enhance community stakeholders to expedite action on its implementation and utilization.

\section{References}

Adekola, P. O., Allen, A. A., Adeloye, D., Olawole-Isaac, A., \& Adediran, O. (2017). An exploratory assessment of Nigeria's performance in millennium development goals (MDGs): Towards a better performance of sustainable development goals (SDGs). IOSR Journal Of Humanities And Social Science, 12(4), 25-37.

Ajiye, S. (2014). Achievements of millennium development goals in Nigeria: A critical examination. International Affairs and Global Strategy, 25(2014), 24-36.

Akpama, S., Bessong, C., \& Bessong, N. (2017). Attainment of the sustainable development goals (sdgs): The relevance of adult basic education. Journal of Faculty of Education, University of Calabar, Calabar-Nigeria, 13(1), 13-20.

Alkire, E. A. (2001). Measuring chronic multidimensional poverty: A counting approach. Paper presented at the A Paper Prepared for the Conference on Income, Weather and Wellbeing in Latin America.

Anigbogu, T., \& Ndubuisi-Okolo, P. U. (2019). Poverty alleviation: The requisite for sustainable development in Nigeria. International Journal of Academic Multidisciplinary Research (IJAMR), 3(3), 25-30.

Ayodeji, A. A. C., Agwu, A. O., Emmanuel, O. A., A., C. O., A., O. O., Aliyu, A. A., . . Jimoh, H. O. (2017). Evaluating the sustainable development goal two (Zero Hunger) in Nigeria: Challenges and lessons from the MDGs. Journal of Sustainable Development in Africa, 19(1), 105-118.

Benyin, A. A., \& Ugochukwu, A. D. (2015). Development and Its challenges in Nigeria: A theoretical discourse. Mediterranean Journal of Social Sciences, 6(6), 275-261.

Business Reporting on the SDGs. (2016). An analysis of goals and targets. A collaborative effort from GRI and the UN Global compact.

Creswell, J. W. (2014). Research design: Qualitative, quantitative and mixed methods approaches (4th ed.). Thousand Oaks, CA: Sage.

Creswell., J. W., \& Plano, C. V. L. (2011). Designing and conducting mixed methods. Thousand Oaks, CA: Sage.

Dike, V. E. (2010). Review of the challenges facing the Nigerian economy: Is national development possible without technological capability. Journal of Sustainable Development in Africa, 12(5), 95-112.

Global Tuberculosis Report. (2015). Geneva: World Health Organization. Retrieved from: http://apps.who.int/iris/bitstream/. [Accessed O5 June 2019].

Igbokwe-Ibeto, C. J. (2015). Issues and challenges in local government project monitoring and Evaluation in Nigeria: The way forward. European Scientific Journal August Edition, 8(18), 180-195.

International Development Association (IDA). (2009). IDA at work community-driven development: Delivering the results people need. Retrieved from: http://www.Worldbank.org/ida Access on 5/5/2019.

International Diabetes Federation. (2017). Diabetes atlas (8th ed.). Brussels: International DiabetesFederation.

Levels and Trends in Child Mortality Report. (2015). Estimates developed by the UN interagency group for child mortality estimation. New York (NY), Geneva and Washington (DC): United Nations Children’s Fund, World Health Organization, World Bank and United Nations.

McMillan, J. H., \& Schumacher, S. (2010). Research in education: Evidence-based inquiry (7th ed.). Boston: Pearson.

MGDs. (2015). Abridged version of Nigeria millennium development goals end-point Report. Retrieved from: www.mdgs.gov.ng.

Mwabu, G. (2007). Health economics for low-Income countries. Center Discussion Paper No. 955.

Ndubuisi-Okolo, P. U., \& Anigbuogu, T. (2019). Insecurity in Nigeria: The implications for industrialization and sustainable development. International Journal of Academic and Applied Research (IJAAR), 3(2), 9-17.

Ogbodo, J. N., \& Okoro, N. M. (2015). Nigerian public awareness and knowledge of the millennium development goals (MDGs) and their level of implementation in Nigeria. European Scientific Journal, 11(23), 301-316.

Rodman, H. (1963). The lower-class value stretch. Social Forces, 42(2), 205-215.Available at: https://doi.org/10.2307/2575693.

Sogunro, O. A. (2015). Motivating factors for adult learners in higher education. International Journal of Higher Education, 4(1), $22-39$.

UN. (2017). The sustainable development goals report. United Nations: New York.

United Nations. (2003). Indicators for monitoring the millennium development goals: Definitions, Rationale, Concepts and Sources. New York: UN.

Uzoagulu, A. E. (2011). Practical guide to writing research project reports in tertiary Institutions (New Edition ed.). Enugu, Nigeria: John Jacob's Classic Publishers Ltd.

World Malaria Report. (2015). Geneva: World Health Organization. Retrieved from: http://www.who.int/malaria/publications/worldmalaria-report. [Accessed 5 June 2019]. 